This is the author's final version of the work, as accepted for publication following peer review but without the publisher's layout or pagination.

The definitive version is available at

https://doi.org/10.1016/j.eiar.2018.01.004

\title{
Are current effectiveness criteria fit for purpose? Using a controversial strategic assessment as a test case
}

Jenny Pope* ${ }^{* a, b, c}$, Alan Bond ${ }^{c, d}$, Carolyn Cameron ${ }^{e}$, Francois Retief ${ }^{c}$, Angus Morrison-Saunders ${ }^{b, c}$

a. Integral Sustainability

PO Box 79

South Fremantle WA 6162

Australia

Ph: +618 94317554

b. School of Science

Edith Cowan University

270 Joondalup $\mathrm{Dr}$

Joondalup WA 6027

Australia

c. Research Unit for Environmental Science and Management

North-West University

Potchefstroom Campus

Private Bag X6001

Potchefstroom 2520

South Africa

d. School of Environmental Sciences

University of East Anglia

Norwich Research Park

Norwich

Norfolk NR4 7TJ

United Kingdom

e. Cameron Strategies

29 Eddy Crescent

Florey ACT 2615

Australia

*corresponding author (jenny@integral-sustainability.net) 


\title{
Are current effectiveness criteria fit for purpose? Using a controversial strategic assessment as a test case
}

\begin{abstract}
The aim of this paper is to test the broader utility of the sustainability assessment effectiveness framework of Bond et al. (2015) by applying it to a controversial strategic assessment case study. The effectiveness framework comprises six dimensions: procedural effectiveness, substantive effectiveness, transactive effectiveness, normative effectiveness, pluralism, and knowledge and learning. It was originally developed to evaluate sustainability assessment at a system-wide level and it has not been previously applied to a specific case study. The analysis was conducted through document review and the first-hand experience of two of the authors who were involved in the case study in different capacities. The case study selected was the strategic assessment of the proposed Browse Liquefied Natural Gas (LNG) Precinct in Western Australia, which was conducted over the period 2007-2015 under the strategic assessment provisions of both the Western Australian and Australian Commonwealth environmental legislation. The framework provided a useful structure within which this complex case study could be explored, its strengths and weaknesses brought to light, and the interactions between the dimensions highlighted. We also found opportunities for refinement of the framework. As a result of this analysis we propose to replace the final three dimensions of the framework with legitimacy, where a legitimate process is one which all stakeholders agree is fair and which delivers an acceptable outcome for all parties, though we acknowledge the need for further conceptualisation of this dimension. We also suggest that the concept of substantive effectiveness should be expanded to incorporate the unintended consequences of impact assessment. Our research thus makes both a useful addition to the literature already published on the Browse case study, as well as to the literature on impact assessment effectiveness.
\end{abstract}

Key words: strategic assessment; effectiveness; legitimacy; Browse LNG Precinct

\section{Introduction}

The question of whether or not impact assessment in its various forms is effective has been a topic of interest and research from the earliest days of impact assessment. It came sharply into focus with the release of the International Study of the Effectiveness of Environmental Assessment in 1996 (Sadler 1996), in which three dimensions of effectiveness were distinguished (p39):

- Procedural: Does the (impact assessment) ${ }^{1}$ process conform to established provisions and principles?

\footnotetext{
${ }^{1}$ Sadler uses the term 'environmental assessment', abbreviated to EA but we prefer the more generic term 'impact assessment'.
} 
- Substantive: Does the (impact assessment) process achieve the objectives set e.g. support well-informed decision-making and result in environmental protection?

- Transactive: Does the (impact assessment) process deliver these outcomes at least cost in the minimum time possible, i.e. is it effective and efficient?

While subsequent researchers seeking to clarify what makes impact assessment effective have largely retained these three dimensions, other dimensions have also been distinguished. For example, Baker and McLelland (2003) include 'normative effectiveness' in their framework for evaluating the effectiveness of an impact assessment process from the perspective of First Nations people, which they define as "the extent to which the policy [EA] achieves the normative goals", where normative goals are "what the policy purports as an ideal with respect to what it sets out to achieve" (p584-585). Authors including Retief (2007) and Runhaar and Driessen (2007) use the term 'indirect effectiveness' to emphasise that impact assessment can deliver substantive outcomes beyond those related to specific decisions as per Sadler (1996)'s conceptualisation. This theme is further developed by Bina, Jing et al. (2011) who prefer the term 'incremental effectiveness'. These broader, more systemic outcomes reflect changes to the context within which impact assessment is conducted (Bina 2008).

Bond, Morrison-Saunders et al. (2013) recently developed an effectiveness framework specifically for sustainability assessment, which they define broadly as any process that directs decision-making towards sustainability (Bond and Morrison-Saunders 2011), a definition derived from Hacking and Guthrie (2008). Six dimensions of effectiveness comprise their framework: procedural, substantive, transactive, normative, knowledge and learning, and pluralism. The inclusion of pluralism invites explicit reflection on the reality that sustainability assessment (and impact assessment in general) will be judged against "diverse and even divergent reference points" (Bond, Morrison-Saunders et al. 2013, p117), while the inclusion of knowledge and learning serves as a reminder that impact assessment can (and arguably should) not only generate new knowledge but also facilitate learning at both the individual and societal levels. This framework was developed in order to "compare and evaluate the effectiveness of sustainability assessment practice in different jurisdictions" (ibid. p117), that is, for application in a 'system-wide review' to use Sadler (1996)'s terminology. It was subsequently applied in their book (Bond, Morrison-Saunders et al. 2013) to emerging practice of sustainability assessment in Canada, England, Western Australia and South Africa. The details of this framework were then slightly modified in Bond, Pope et al. (2015).

The aim of this paper is to test the broader utility of the Bond, Pope et al. (2015) effectiveness framework by applying it to a specific case study rather than a system in an example of what Sadler (1996) terms a 'decision audit'. We are also interested in evaluating the utility of the framework in application to other forms of impact assessment apart from sustainability assessment, and so we choose a strategic assessment case study in this instance. We do this in order to determine the extent to which application of the framework illuminates the relative strengths and weaknesses of this case study, and hence the extent to which the framework can be considered a useful tool in the evaluation of impact assessment case studies in general. The evaluation aims to identify specific modifications that might make the framework more generally applicable to individual assessments rather than systems. 
We commence in Section 2 by briefly introducing our selected case study and explain the reasons for its selection, before outlining the methods for applying and testing the framework. We describe the effectiveness framework of Bond et al. (2015) in Section 3 and modify it to fit the specific context of a strategic assessment; and we provide details of the selected case study in Section 4 . We then apply the framework to the case study in Section 5, discuss the outcomes in Section 6, and draw conclusions in Section 7.

\section{Case study selection and embedded methods}

The case study to which the framework is applied in this paper is the strategic assessment ${ }^{2}$ of the proposed Browse Liquefied Natural Gas (LNG) Precinct in Western Australia, a process conducted over the period 2007-2015. While it is often argued that the goal of strategic assessment in particular should be to seek to contribute to sustainability (International Association for Impact Assessment 2002, Wallington, Bina et al. 2007), making it a form of sustainability assessment according to the definition provided above, the concept of sustainability was not specifically invoked in this case. Thus the case study offers the opportunity to explore the utility of the Bond et al. (2015) effectiveness framework to impact assessment more broadly.

This particular case study was selected because it was complex and highly controversial, implying that there were aspects of the process which were perceived by some to be ineffective. It has also been the subject of previous contributions to the academic literature that have critiqued it from different angles including through a social impact assessment lens (Beckwith 2012); an Indigenous People's perspective (O'Faircheallaigh 2009); and an institutional and legal perspective, with a focus on the marine environment (Marsden 2013). The depth of existing understanding and analysis of this case study was an important factor in its selection for two reasons:

1. The published critiques form an important part of our dataset, along with documentation associated with the assessment process and the reflections of two of the authors who were involved in the case study in different capacities over its duration, one as a Government employee and the other as a consultant to both Government and the private sector; and

2. It enables us to examine whether the effectiveness framework of Bond et al. (2015) sufficiently captures the full range of values and opinions that are brought to bear in a contentious context.

To test the value of the framework in Section 4 we draw on the three data sources identified above to apply it to the case study using our professional judgement, acknowledging that this process is inherently subjective. We also acknowledge the limitations of document review as our data collection method; further insights into the effectiveness of the case study could be obtained by interviewing stakeholders and interested parties. However, we believe that our approach is sufficient for our stated aim of testing the utility of the framework. Our analysis also provides further evaluation of and insights into a case study that has attracted international attention.

\footnotetext{
${ }^{2}$ We use the Australian terminology 'strategic assessment' throughout, rather than the more common international term 'strategic environmental assessment'.
} 


\section{An effectiveness framework for strategic assessment}

Each of the six dimensions of the Bond, Pope et al. (2015) effectiveness framework is discussed in turn below in the context of strategic assessment, with modified wording as indicated.

\subsection{Procedural effectiveness}

Procedural effectiveness refers to how an assessment process is undertaken, i.e. the steps that are followed. Procedural effectiveness is noted to be dominant in many effectiveness studies (for example Wood 2003, Jones, Baker et al. 2005), as well as in the International Association for Impact Assessment's (IAIA's) Strategic Environmental Assessment Performance Criteria (International Association for Impact Assessment 2002), which represent good practice guidance for strategic environmental assessment (Bina, Jing et al. 2011). In relation to procedural effectiveness Bond, Pope et al. (2015) ask: Have appropriate processes been followed that reflect institutional and professional standards and procedures?

While Sadler (1996) refers to conformance with 'established provisions and principles', Bond, Pope et al. (2015) highlight that what constitutes 'professional standards and procedures' is often highly dependent upon the political, legislative and institutional context, a point also made by Fischer (2002), Fischer and Gazzola (2006) and Van Doren, Driessen et al. (2013). Nevertheless, there are some basic elements of accepted good practice in strategic environmental assessment, including whether the scoping is appropriate; whether alternatives are considered; whether integrated, fit-forpurpose information is generated at the appropriate time; and whether the process is participatory, transparent and accountable (International Association for Impact Assessment 2002, Wood 2003, Jones, Baker et al. 2005). This list can be used as the basis for the evaluation of a specific case study, whereas a system-wide evaluation might be more concerned with whether or not appropriate procedures are in place within a given jurisdiction.

\subsection{Substantive effectiveness}

Substantive effectiveness refers to the extent to which the intended outcomes of the assessment process are achieved (Van Doren, Driessen et al. 2013). While many authors distinguish between direct (decision-related) and indirect/incremental (broader, system-wide) outcomes as previously discussed, Bond, Pope et al. (2015) define substantive effectiveness broadly to include both. They ask: In what ways, and to what extent does (strategic) assessment lead to changes in process, actions, or outcomes?

Considerations of direct substantive effectiveness relate to the extent to which the assessment process informs decision-making, for example whether new alternatives were identified as a result of the assessment process, whether appropriate mitigation measures were identified and incorporated, and whether the assessment influences the subsequent decisions made about that proposal (Theophilou, Bond et al. 2010, Bina, Jing et al. 2011, Bond, Morrison-Saunders et al. 2013, Chanchitpricha and Bond 2013). Indirect or incremental substantive outcomes could include changes to processes, policies and legislation, capacity building and awareness, knowledge generation and learning, and gradual shifts in societal values and norms (Retief 2007, Bina, Jing et al. 2011).

\subsection{Transactive effectiveness}

Transactive effectiveness refers to how efficient an impact assessment process is, in terms of time and cost (Chanchitpricha and Bond 2013). While some authors have apparently considered these as 
secondary concerns and omitted transactive effectiveness from their discussions (e.g. Bina, Jing et al. 2011), it has recently been argued that a failure to demonstrate transactive effectiveness in an era of economic rationalism and cost-cutting puts at risk the future of impact assessment itself (Bond, Pope et al. 2014, Morrison-Saunders, Pope et al. 2014). In relation to transactive effectiveness, Bond, Pope et al. (2015) ask: To what extent, and by whom, is the outcome of conducting (strategic) assessment considered to be worth the time and cost involved?

\subsection{Normative effectiveness}

As previously described, normative effectiveness refers to whether the impact assessment process achieved its ideal, normative goals (Baker and McLelland 2003). This clearly raises the question as to what such ideal, normative goals should be, and the argument has been made that the overarching goal of impact assessment in general, and particularly strategic level assessment, should be a contribution to sustainability (International Association for Impact Assessment 2002, Baker and McLelland 2003, Wallington, Bina et al. 2007, Sheate 2009). Reflecting their specific focus on sustainability assessment Bond, Morrison-Saunders et al. (2013) drew on the work of Gibson (2013) to provide clarity within their effectiveness framework on what the normative goals of sustainability assessment should be from a societal perspective, but subsequently retreated from this certainty in Bond, Pope et al. (2015) to acknowledge that how sustainability is defined will depend upon the particular sustainability discourse to which different stakeholders subscribe. In relation to normative effectiveness, Bond, Pope et al. (2015) ask: Does the (strategic) assessment meet the expectations of stakeholders irrespective of the sustainability discourse they align with?

\subsection{Pluralism}

Pluralism refers to the different value systems and perspectives held by different stakeholders and how these are managed within an impact assessment process (Bond, Dockerty et al. 2011). The need to acknowledge and to engage with pluralism is argued to be vital to any meaningful discussion of impact assessment effectiveness and indeed any impact assessment process (Cashmore, Gwilliam et al. 2004, Cashmore, Richardson et al. 2010, Bond, Dockerty et al. 2011, Bond, Morrison-Saunders et al. 2013, Rozema and Bond 2015). To emphasise this, the framework of Bond, Pope et al. (2015) includes pluralism as a distinct dimension, and one which influences the four core dimensions of procedural, substantive, transactive and normative pluralism. They ask: How, and to what extent, are affected and concerned parties accommodated into and satisfied by the (strategic) assessment process?

This question goes beyond the need for providing opportunities for public participation in line with what is considered good practice, which is addressed as a component of procedural effectiveness (see Section 3.1), to also consider the extent to which stakeholders are satisfied by this engagement.

\subsection{Knowledge and learning}

Knowledge and learning refers to the recognition that effective impact assessment facilitates learning in various forms (Jha-Thakur, Gazzola et al. 2009, Sánchez and Morrison-Saunders 2011, Bond, Morrison-Saunders et al. 2013). Bond, Morrison-Saunders et al. (2013) follow Nilsson (2005) to distinguish between instrumental and conceptual learning, where the former refers to the acquisition of new knowledge within an existing frame and the latter refers to a modification in frame (also analogous to Argyris and Schön (1996)'s single and double-loop learning). With respect 
to knowledge and learning, Bond, Pope et al. (2015) ask: How, and to what extent, does the (strategic) assessment process facilitate instrumental and conceptual learning?

While both forms of learning can occur within a single impact assessment process by various stakeholders (see for example Pope 2007, Cashmore, Bond et al. 2008), impact assessment practice also offers the (potentially greater) potential for learning and hence improvement in governance over time. Thus learning is the mechanism through which both direct and indirect substantive outcomes (Section 3.2) can be delivered.

\section{Case study: The strategic assessment of the proposed Browse Liquefied Natural Gas (LNG) Precinct in Western Australia}

In June 2007, the Government of Western Australia announced its intention to identify and assess a potential site for a multi-user liquefied natural gas (LNG) precinct for processing gas from the Browse Basin off the north west coast of Western Australia (NDT 2008a). This decision was made in response to discoveries of significant reserves of natural gas in the Browse Basin by a number of oil and gas companies, including Woodside, Shell and Inpex, and concerns that this could lead to ad hoc development of LNG processing plants across the relatively unindustrialised Kimberley region, the nearest land to the gas reserves. The Government of Western Australia proposed the multi-user precinct concept as a way of minimising infrastructure duplication and managing the cumulative impacts of LNG development (DSD 2010a), while facilitating resource development in Western Australia. It seems likely that the decision of Inpex to develop their facility for processing Browse Basin gas in Darwin, Northern Territory rather than in Western Australia was one of the triggers for this initiative (O'Faircheallaigh 2015).

The concept of a Government-led site selection process initially had broad community support within Western Australia. The (Indigenous) Traditional Owners of the land, represented by the Kimberley Land Council (KLC), together with a number of local and international environmental groups (including WWF, Environs Kimberley, The Wilderness Society, the Australian Conservation Foundation and the Conservation Council of Western Australia) issued a Joint Position Statement in December 2007 expressing their support, subject to Traditional Owners having "a key role in all land management programs in the Kimberley in order to achieve environmental and cultural management benefits" (http://assets.wwfau.panda.org/downloads/wa018 joint position statement kimberley Ing 6dec0 7.pdf). The Government of Western Australia, under then Premier Alan Carpenter, made the commitment that the proposed LNG development would only go ahead with the consent of the Traditional Owners (Carpenter 2006). The Traditional Owner Taskforce (TOTF), representing all Native Title claim groups along the Kimberley Coast, was established as an administrative body supported by public funds to ensure that commitments to Indigenous involvement in the process were given effect (O'Faircheallaigh 2015).

The process of identifying and assessing a suitable site was a long and complex one. It commenced with a non-statutory site selection process led by the Government of Western Australia, followed by the simultaneous development and assessment of the Kimberley LNG Precinct Master Plan under the strategic assessment provisions of both the Western Australian Environmental Protection Act 1986 (EPAct (WA)) and the Commonwealth Environment Protection and Biodiversity Conservation Act 
1999 (EPBCACt (Cth)) $)^{3}$. The assessment of alternatives (in this case alternative sites) was therefore outside the statutory strategic assessment processes, which was more akin to a large project-level assessment than to strategic environmental assessment as practised in other parts of the world (Marsden 2013). For the purposes of this paper, however, we consider the 'strategic assessment process' to include both the site selection process and the statutory strategic assessment conducted under both State and Commonwealth legislation. This is consistent with the way in which the process was communicated and explained in the Strategic Assessment Report itself (DSD 2010a), and within the Strategic Assessment Agreement ${ }^{4}$ between the Western Australian and Commonwealth Governments, which was signed in February 2008.

The site selection process was led by the Northern Development Taskforce (NDT), a non-statutory body appointed by the Government of Western Australia, over the course of 2008 based upon Terms of Reference (ToR) released in October 2007 by the Western Australian Department of Industry and Resources (DoIR 2007). The process initially involved reviewing 43 potential sites in the Kimberley that had been previously identified by industry, and evaluating them against a range of criteria with the support of various technical working groups and consultants. A short-list of 11 sites deemed to be technically feasible by consultants Gaffney, Cline and Associates (GCA 2008) appeared in the NDT Interim Report of June 2008, including two new sites suggested by the Traditional Owners (NDT 2008a) which emerged through the parallel site selection process conducted by the TOTF. The subsequent NDT Site Selection Report of September 2008 further refined the short-list to four sites based upon application of criteria covering environmental and social as well as technical considerations (NDT 2008b): North Head, Anjo Peninsula (one of the sites proposed by the Traditional Owners), Gourdon Bay and James Price Point (which was not one of the sites initially reviewed by CGA but which appeared in the short-list of 11). These four sites were also announced in September 2008 to be still under consideration by the Traditional Owners ${ }^{5}$, although Gourdon Bay was withdrawn from the TOTF short-list in mid-December 2008 on environmental grounds (O'Faircheallaigh 2015). The NDT Site Selection Report was subject to public comment, and the NDT Final Site Evaluation Report was released in December 2008 (NDT 2008c). The environmental implications of these four sites were assessed by the Western Australian Environmental Protection Authority (EPA) under s16e of the EPAct, which allows for the EPA to make strategic advice to Government on any matter.

A significant factor influencing the trajectory of the NDT process and everything that followed was the change in Government of Western Australia in September 2008 from Labor to a Liberal government (which, politically, many jurisdictions would recognise as being conservative) headed by Premier Colin Barnett (O'Faircheallaigh 2015). In October 2008, when four sites were still under consideration, the new Premier announced that North Head was his preferred site for the LNG

\footnotetext{
${ }^{3}$ Australia is a federation in which each of the six States and two Territories has its own environmental legislation in addition to eh Commonwealth legislation which is specifically concerned with Matters of National Environmental Significance (MNES). Thus EIA is often required at both State/Territory and Commonwealth levels.

${ }^{4}$ Strategic Assessment Agreements (SAAs) between proponents and the Commonwealth Department of Environment are the mechanisms that formalise the intent to undertake a strategic assessment. In this case the SAA was a political agreement between two Labor governments.

${ }^{5}$ The TOTF included the area from Quondong to James Price Point as one of their four sites still under consideration (O'Faircheallaigh 2015).
} 
Precinct. In December 2008, the EPA issued advice concluding that Gourdon Bay was the least environmentally constrained of the four sites (EPA 2008) and that North Head was "not suitable for large scale industrial development from an environmental point of view". The Premier promptly announced the selection of James Price Point, $60 \mathrm{~km}$ north of the pearling and tourism centre of Broome, as the preferred precinct location (EPA 2008).

Whilst the NDT did give some consideration to potential Precinct sites in the Pilbara region further south, an area already highly industrialised, this option was quickly dismissed on mainly cost grounds (NDT 2008b) as were potential sites in the Northern Territory (a separate jurisdiction from Western Australia), even though Inpex's decision to develop there would appear to have confirmed it as a viable option (NDT 2008c). The focus of the NDT's work remained firmly on the Kimberley throughout. This was consistent with its Terms of Reference which do not specifically call for evaluation of sites outside the Kimberley (DoIR 2007) but inconsistent with the requirement of the Strategic Assessment Agreement for "(a)n analysis of technically and economically viable gas processing options outside the Kimberley" ${ }^{\prime \prime}$. It also appears that the NDT only delivered on one of its specified functions (to recommend a suitable site for gas processing) and not the other four functions allocated to it, which included "a whole-of-government communication strategy on the Government's approach to balanced sustainable development" and "a recommended model for Indigenous participation in resource development, including appropriate negotiation protocols, a comprehensive benefits package for Traditional Owners and regional, State and Commonwealth benefits distribution models" (DoIR 2007, p5).

The statutory strategic assessment of the proposed Precinct site at James Price Point was then conducted under both the EPACt (WA) and the EPBCACt (Cth). It is important to note that beyond the nomination of James Price Point as the location for the Precinct, no further details were available at the commencement of the statutory assessment process. The development of the Kimberley LNG Precinct Master Plan occurred concurrently with the strategic assessment, with the assessment process informing the development of the Master Plan. The Strategic Assessment Agreement of February 2008 committed the Commonwealth and Western Australian Governments to a collaborative and coordinated assessment process meeting the requirements of both pieces of legislation. The Terms of Reference for the strategic assessment required that the impacts of the proposed development on Aboriginal people be considered, as well as how Aboriginal people could be involved in the potential maangement of those impacts, while the detailed Scope of the Strategic Assessment that was subsequently released in August 2009 also included the requirement for a broad range of social impacts to be considered. The KLC commissioned a comprehensive Indigenous Impacts Assessment with the financial support of the Government of Western Australia. The explicit inclusion of the social dimension represented something of a change of direction for both regulators, because the WA EPA does not believe it has a mandate to consider the broader social or economic implications of a proposal and hence has a predominantly biophysical focus (Bache, Bailey et al. 1996), and the Commonwealth Department of the Environment focuses on the primarily biophysical Matters of National Environmental Significance (MNES) under the EPBCAct (Cth), despite having a

\footnotetext{
${ }^{6}$ The Commonwealth Government also commissioned a separate study into alternative sites outside the Kimberley (GHD 2009).
} 
mandate to consider sustainable development more generally, particularly at the strategic level (Marsden 2013).

The proponent for the Browse LNG Precinct proposal, and therefore the party responsible for the strategic assessment, was the Western Australian Department of State Development (DSD), a point that was not well understood by the general community or the media. This confusion was partly due to the important role that Woodside Energy Limited played in the strategic assessment as the potential 'foundation proponent' of the Precinct, i.e. the first proponent to take up one of the available plots within the Precinct (leaving one other available for future potential developers). The Heads of Agreement between Woodside, the Government of Western Australia and the KLC was signed in August 2009 and the subsequent Preliminary Development Agreement was signed a month later. The status of foundation proponent effectively made Woodside a partner of the Government of Western Australia (DSD 2010a), and responsible for commissioning many of the specialist reports required by the strategic assessment scoping document. Woodside was also active throughout the period of the strategic assessment in planning for their proposed Browse LNG development on the new Precinct, and hence was very much in the public and media spotlight throughout this period.

An important point to note here is that although strategic assessment under both the EPAct (WA) and the EPBCACt (Cth) is voluntary (the decision to submit a proposal for strategic assessment is made by the proponent), it results in an endorsed plan with possible approval (in the case of the Commonwealth) or an approved strategic proposal (in the case of Western Australia), both with legally binding conditions. Subsequent project proposals deemed to be consistent with an approved plan or strategic proposal can be declared 'approved actions' (under the EPBCAct (Cth)) or 'derived proposals' (under the EPAct (WA)) and as such are exempt from project-level environmental impact assessment (EIA) provided these conform with the legally binding conditions of the strategic approval. This is a significantly different regulatory approach from strategic assessment conducted in other parts of the world (e.g. within the EU under the EU Strategic Environmental Assessment Directive) (Stoeglehner, Morrison-Saunders et al. 2010). The streamlining effect of strategic assessment in Australia is in fact its main raison d'etre, and the reason why it is attractive for potential project proponents such as Woodside to engage with it.

The Kimberley LNG Precinct Master Plan, nominating James Price Point as the chosen site for the LNG Precinct and defining the activities that could take place within the Precinct was released in September 2010, and the Browse LNG Precinct Strategic Assessment Report was released three months later in December 2010, for a 12 week public comment period. Numerous technical reports were still missing from the Strategic Assessment Report at that point, due largely to difficulties obtaining access to the land in order to conduct the necessary surveys. Additional technical reports were prepared and provided to the EPA as supplementary information throughout 2011 and even 2012, after the submission of the final Strategic Assessment Report and response to public submissions were provided by DSD to the EPA in December 2011. It was perceived by some that the Strategic Assessment Report was deficient in a number of areas; in particular the consideration of sites outside the Kimberley was deemed to be cursory and inconsistent with the evaluation of the Kimberley sites. It was also argued that the significance of identified negative environmental and social impacts was downplayed in the report (The Wilderness Society 2010). 
By this period of 2010-2012, the initial widespread support for the proposed LNG precinct and the strategic assessment had fallen away. The process had become highly controversial and firmly in the media spotlight (see for example Burrell 2011). Opposition manifested in widespread protests in the region and in Perth, international media attention, highly publicised protests and blockades at the James Price Point site from around mid-2011, and a number of legal challenges, some of which were successful in overturning key decisions. The grounds for concern were related not only to the potential environmental impacts of the proposal and the potential impacts on the town of Broome and its tourism industry, but to the treatment of the Traditional Owners in the process, following the change in Government in Western Australia in September 2008.

While the support and consent of the Traditional Owners was originally a key plank of the overall process, trust had been undermined by the threats (subsequently carried out) of the Barnett Government to compulsorily acquire the land anyway, if consent could not be reached amongst the Traditional Owner Groups within the Government's preferred timelines. As articulated by O'Faircheallaigh (2015), p54, there was a marked shift from a process to determine "whether or not an LNG Precinct site could be found that met relevant engineering, technical and environmental requirements and also had the support of Traditional Owners for the area concerned. Now the central issue was how negative impacts associated with a choice of site made by the State without Aboriginal consent could be minimised, while at the same time allowing Traditional Owners and other affected Aboriginal people to share in the benefits of development". A benefits package to the value of \$AUD 1.5 billion over 30 years was negotiated between the Government of Western Australia and some of its agencies, Woodside and the Tradional Owners.

In July 2012, the Western Australian EPA recommended that the strategic proposal to develop an LNG processing facility at James Price Point be approved subject to strict environmental conditions. This catalysed the introduction of the Browse (Land) Agreement Bill introduced to Parliament, confining onshore gas processing to one site in the Kimberley. Woodside's proposed development was then declared to be a derived proposal by the EPA in December 2012, meaning that no projectlevel EIA would be required as long as the project conformed with the conditions arising from the strategic assessment. The final strategic assessment documentation was then submitted by the Government of Western Australia to the Commonwealth for verification that the requirements of the strategic assessment had been met. The final step would have been the decision by the Commonwealth Minister for the Environment whether or not to endorse the Kimberley LNG Precinct Master Plan, but the endorsement decision was never made as events overtook the process (and there is no statutory timeframe for decisions on strategic assessments under the EPBCAct (Cth)).

In April 2013, Woodside announced it was abandoning its proposed project in its present form, citing development costs as the reason and signalling an intent to investigate alternative development options for the Browse field. This was hailed as a victory by the protest movement. Shell, a joint venture partner in Woodside's project, immediately announced its desire to use floating LNG technology to develop the resource. Woodside subsequently withdrew from the Browse LNG Precinct Project Agreement and Regional Benefits Agreement, in which the \$AUD 1.5 billion Indigenous benefits package was articulated, releasing it from its obligations to contribute to these benefits. In August 2013, the Supreme Court of Western Australia ruled in favour of the Wilderness Society, which had challenged the legality of the EPA's recommendation to Government to approve the Precinct proposal challenge on grounds of four of the five EPA Board members having financial 
interests in Woodside's project and therefore being conflicted. Although these interests had been declared and the final decision to recommend was made by the Chair of the EPA alone, it was successfully argued that the final decision had been informed by numerous other discussions and decisions involving all five board members. At this point there was not only no foundation proponent, but no approved Precinct site either. ,

The strategic proposal was eventually approved by the Government of Western Australia under the EPAct in mid-2015 after a special three-person Board was appointed by the Government of Western Australia to re-assess it. By this point however there were no prospective project proponents interested in developing on the site since the oil price had plummetted earlier that year, and the eventual approval of the Precinct passed almost unnoticed by the media and general public. However, there is a legacy. As highlighted by Beckwith (2012) and Wesley (2013), communities (both Indigenous and non-Indigenous) were sharply divided over the James Price Point proposal, with significant impacts on community cohesion. Furthermore, there have been socio-economic impacts associated with the creation of expectations that never manifested, evident in falling house prices, failed businesses, and a population exodus from Broome (Wesley 2013). Beckwith (2012) calls this 'collateral social damage'.

This very simplified summary describes the trajectory of a process that commenced with good intentions and broad support, but which degenerated into controversy and conflict, the scars from which have been felt by the communities in the region, both Indigenous and non-Indigenous, way beyond the period of the assessment (Beckwith 2012, Wesley 2013). There is a strong general impression within the community that the strategic assessment process failed in some fundamental way or ways. In the following section we reflect upon the Browse LNG Precinct strategic assessment by evaluating it against the sustainability assessment effectiveness framework of Bond, Pope et al. (2015) to determine the extent to which this framework can aid understanding of this case study, particularly considering whether this framework adds value over the critiques already published in the academic literature (Beckwith 2012, Marsden 2013, O'Faircheallaigh 2015).

\section{Evaluating the effectiveness of the Browse LNG Precinct strategic assessment}

The discussion is structured according to the six dimensions of the sustainability assessment effectiveness framework of Bond, Pope et al. (2015), and guided by the questions identified for each dimension as presented in Section 3.

\subsection{Procedural effectiveness}

Have appropriate processes been followed that reflect institutional and professional standards and procedures?

It is somewhat difficult to determine whether 'appropriate processes' were followed in this case, because at the time it was conducted there was very limited guidance available for the conduct of strategic assessments under the EPBCAct (Cth) and none at all for the EPAct (WA). Hence there was no clear context-specific definition of 'appropriate processes'. However, we use accepted international best practice as our benchmark for 'appropriate procedures'. We discuss each of the 
best practice considerations outlined in Section 3.1 in turn, also reflecting on compliance with the Strategic Assessment Agreement where relevant.

The scope of the Browse assessment process was articulated in the Scope of the Strategic Assessment, and as previously mentioned, included consideration of the social impacts as well as the biophysical ones. There was, however, no attempt to integrate the social and environmental information, and in fact both the Social Impact Assessment Report and the Indigenous Impacts Report appear as appendices to the main Strategic Assessment Report, and receive little focus in the main document (Beckwith 2012).

Consideration of alternatives was the focus of the NDT site selection process within the broader Browse strategic assessment process, and also a requirement of the Strategic Assessment Agreement. However, as discussed in the previous section, consideration of sites outside the Kimberley was not meaningfully undertaken by the NDT. Beckwith (2012) suggests that it was always unrealistic to expect serious consideration to be given by the Government of Western Australia to sites in the Northern Territory (outside Western Australia) because this would mean that economic benefits would not flow to Western Australia. The cursory nature of the consideration by the NDT of sites outside the Kimberley was widely perceived as a significant flaw in the process. Furthermore, even at the point by which four Western Australian sites had been short-listed there was evidence of political interference in the site selection process. As discussed in Section 4, the new Premier of Western Australia, Colin Barnett, announced his preferred site before the EPA had undertaken its environmental assessment of the four short-listed sites, and subsequently (somewhat embarrassingly) had to retract his announcement. The subsequent EPA report is very carefully worded and identifies James Price Point as the 'least constrained site on the Dampier Peninsula' (EPA 2008). Therefore, although there was stated intent to robustly review a broad range of sites, in reality the consideration of alternative sites was restricted and politically influenced.

While comprehensive technical and environmental information was collated through the NDT site selection process, Beckwith (2012) points out that there was a lack of specialised social impact expertise at this stage even though social concerns were used to help justify the selection of James Price Point and to reject consideration of the Pilbara sites. Marsden (2013) argues that the statutory strategic assessment should have been applied to 'all reasonable sites', not just one preferred site. Had the strategic assessment been applied to the four short-listed sites for example, this would have required the same quality and breadth of information as was eventually gathered for James Price Point to be collected for all four sites, which would have greatly enhanced the robustness of the site selection process. It is important to note, however, that the Strategic Assessment Agreement only required statutory strategic assessment of the preferred site.

With respect to the quality and timeliness of the information generated during the statutory strategic assessment process, many environmental specialist reports were missing from the Strategic Assessment Report when it was published in December 2010. Difficulties in conducting the Social Impact Assessment (SIA) and Aboriginal Social Impact Assessment (ASIA) (a component of the Indigenous Impacts Assessment) due to uncertainties regarding project timing being more significant than for the biophysical environmental assessment were noted by Beckwith (2012). A range of development scenarios was applied in the SSIA to address this issue. The inadequate timelines available for the conduct of the ASIA were also noted (O'Faircheallaigh 2015). 
The level and quality of stakeholder engagement, and particularly the engagement of the broader community in the whole process has been widely criticised (Beckwith 2012, Wesley 2013), and transparency and accountability are also questionable given the apparent political interference in the process.

In summary, we consider the procedural effectiveness of the Browse LNG Precinct strategic assessment to have been limited when compared with international best practice.

\subsection{Substantive effectiveness}

In what ways, and to what extent does the assessment lead to changes in process, actions, or outcomes?

The focus in this section is on direct substantive outcomes, i.e. those directly related to this process and decision-making around it, since our methodology does not enable analysis of the broader indirect substantive outcomes that may or may not have arisen as a result.

With respect to informing decision-making, the site selection process, with its multi-criteria approach to comparing a large number of potential sites, did demonstrably inform the decisionmaking process that ultimately led to the selection of James Price Point as the preferred site. This is evidenced by the fact that sites deemed unsuitable were eliminated in a staged approach. In turn it is evident that the parallel site selection process undertaken by the TOTF influenced the NDT site selection process since two new sites proposed by the Traditional Owners were added to the NDT's list and evaluated. It is also evident that the environmental information gathered during the site selection process formed the basis of the EPA's strategic advice to Government on the four shortlisted sites (EPA 2008). It could be argued that the selection of James Price Point by the Premier was inconsistent with the EPA's advice that Gourdon Bay was the least environmentally constrained site, but under the Western Australian system the final decision is always political, and given the withdrawal of the TOTF's support for Gourdon Bay, it would have been politically difficult for this site to have been selected. Nevertheless the Premier's preference, changing from North Head to James Price Point, was based on EPA findings and therefore represents a substantive outcome of sorts. Furthermore, the EPA's advice was based principally upon biophysical environmental considerations, while the Government had a broader perspective.

The point was made in the previous section that assessment of social impacts was weak at the site selection stage and therefore that social considerations did not adequately inform this decisionmaking. Under the Western Australian, and to some extent also the Commonwealth, system, social issues receive little consideration under the respective pieces of environmental legislation and hence there is a lack of a clear mechanism through which this influence could have occurred, despite the inclusion of social issues in the Strategic Assessment Agreement and Scope of the Strategic Assessment. This is a system issue, rather than one specific to this case study.

It is less evident that the subsequent statutory strategic assessment was substantively effective. Firstly, it is not clear that the data generated through the various specialist studies completed were adequately taken into consideration; for example The Wilderness Society (2010) argued that the significance of both terrestrial and marine environmental impacts was downplayed in the Strategic Assessment Report with potential consequences for decision-making. Furthermore, as discussed in Section 4, many of the technical studies were not complete by the time the Kimberley LNG Precinct 
Master Plan was released and therefore clearly did not influence the development of the plan ${ }^{7}$. Secondly, doubts were raised over the extent to which some of the mitigations proposed in the Strategic Assessment Report would actually be effective in managing the impacts. This was particularly the case for the Social Impact Assessment Report, in which a range of management plans were proposed with little or no detail of what these plans would contain, commensurate with the lack of detail about the timing of any projects that might be developed within the Precinct and therefore the difficulty of predicting social impacts (see previous section). Furthermore it was unclear through which mechanism these social impact management plans would be mandated, implemented and monitored, given the lack of any legislative framework for social impacts in Western Australia (Beckwith 2012). The inability to deliver substantive social outcomes in this case is a function of the lack of procedural effectiveness at the system level.

Ultimately, however, it could be said that the strategic assessment process did eventually achieve its substantive goal of delivering an approved site for an LNG processing precinct, and therefore we conclude that the Browse LNG Precinct strategic assessment was to some extent substantively effective in terms of informing decision-making. The fact that there is now no proponent on the horizon to build on the site is somewhat ironic. Given the fact that the site has not, and may never be developed, it is not possible to determine whether or not the assessment achieved the goal of protecting the biophysical environment. Unfortunately, there have been unintended negative outcomes on the ground with respect to the social conditions in Broome and the surrounding region, as discussed in Section 4.

\subsection{Transactive effectiveness}

To what extent, and by whom, is the outcome of conducting the assessment considered to be worth the time and cost involved?

As previously explained, future projects that are deemed to be consistent with the strategic proposal or plan are exempt from project-level EIA under both the Commonwealth and Western Australian systems. This situation makes it difficult to assess whether or not a strategic assessment process was worth the time and cost until a subsequent project proposal has been approved. In the Browse case, given that there is no longer a project proposal on the horizon, it would have to be said that the strategic assessment was not worth the time or money. Even if development had proceeded at James Price Point, the fact that the site selection process commenced in 2007 and the final approvals for the Precinct site were not given until mid-2015, most stakeholders would likely argue that the process was still not worth the time and money, though this is an assumption on the part of the authors.

It is important to note that the NDT site selection process itself appears to have been efficient, with the Terms of Reference issued in October 2007 and the Interim Report issued in June 2008, followed by the Site Evaluation Report in September 2008 and the Final Site Evaluation Report in December 2008, closely followed by the EPA's strategic advice (EPA 2008). There is evidence to suggest, however, that the Liberal government that came to power in September 2008 perceived that even the site selection process was taking too long. This was evidenced by the premature announcement by the Premier of his preferred site before the EPA had provided advice on the four short-listed sites

\footnotetext{
${ }^{7}$ For example, subsequent heritage surveys found dinosaur footprints in the area proposed for the integrated marine facility at James Price Point, requiring modification to the site layout.
} 
and the application of a three month deadline for the negotiation of the Heads of Agreement under the threat of compulsory acquisition of traditional lands, which put considerable pressure on the Traditional Owners to speed up their decision-making processes. Such actions have also been perceived as political interference in the process (The Wilderness Society 2010, O'Faircheallaigh 2015). Significant time pressure was also applied on the conduct of the Aboriginal Social Impact Assessment (O'Faircheallaigh 2015), and the Strategic Assessment Report released in December 2010 was still missing a considerable number of specialist reports that had not been completed at the time of publication and were only made available to the public and the EPA throughout the course of 2011 and 2012. It could be argued that the drive for transactive effectiveness compromised the procedural and hence the substantive effectiveness of the process.

It is therefore somewhat ironic that the statutory strategic assessment process was considerably slowed down by a series of legal challenges throughout 2011 - 2013. These challenges related to the legality of the compulsory acquisition notice issued by the Government [McKenzie v Minister for Lands [2011] WASC 335 (6 December 2011)]; the legality of Woodside commencing road works on the Precinct site prior to approval of the strategic proposal (case dismissed May 2012); and the conflict of interest of the EPA Board members discussed in the previous section (August 2013). As previous discussed, this final challenge meant that approval for the Precinct site was not issued until mid-2015.

In summary, it is probably fair to say that the NDT site selection process demonstrated transactive effectiveness by virtue of its efficiency, but the statutory strategic assessment processes did not, and that attempts to expedite the process only served to slow it down by attracting controversy, as well as undermining its procedural and substantive effectiveness.

\subsection{Normative effectiveness}

Does the assessment meet the expectations of stakeholders irrespective of the sustainability discourse they align with?

As explained in Section 3.4, Bond et al. (2015) defined the concept of normative effectiveness in terms of whether the normative goal of an assessment process is acceptable to a range of stakeholders who may have very different value sets and subscribe to very different views of what a sustainable future looks like. In this case there was very little explicit engagement with the concept of sustainability and no clear articulation of the normative goals to be achieved, leaving them open to interpretation by different stakeholders and subject to change according to the shifting political landscape. Marsden (2013, p13) offers the following interpretation of this:

"The reason why the WA Government pursued so vigorously the onshore hub at James Price Point arguably had less to do with avoiding the most environmentally and culturally significant areas of coast but more to do with restricting significant developments to one precinct on the Kimberley coast, finding a site relatively close to existing infrastructure (in the regional city of Broome) to manage costs for State-funded services, and to ensure that gas was processed onshore to maximise benefits to WA".

As highlighted by Marsden (2013), the whole process had a clear pro-development framing, in that the starting point was the desire to find a suitable site for LNG processing. As Beckwith (2012, p91) argues, perhaps this was a missed opportunity to ask different questions, such as: 
1. What is the best path to achieving an ecologically and socio-economically sustainable future for the Kimberley region?

2. How can the wealth generated by regional oil and gas resources best be used to lift the standard of living of people in the Kimberley?

3. Can the Precinct significantly reduce the socioeconomic disadvantage of Aboriginal communities in the region and not create an unacceptable burden of negative impacts?

4. Is a State-owned and managed gas precinct the best approach to facilitate environmentally and socioeconomically responsible development of the Browse Basin's gas resources?

Questions 2 and 3 in particular are inherently normative, and representative of a particular worldview or sustainability discourse. Arguably questions 1 and 4 could be more strategic 'decision questions' (Morrison-Saunders and Thérivel 2006, Pope and Grace 2006) that could open up the opportunity for a more inclusive conversation about sustainable futures, and thus potentially deliver on normative effectiveness. It has been argued that ideally a sustainability-oriented impact assessment would commence by defining a sustainable outcome would look like for the situation at hand, a 'sustainability vision' in other words (Hartz-Karp, Pope et al. 2015). The creation of this vision would engage a wide range of stakeholders holding different views and subscribing to different sustainability discourses, and would necessarily be a compromise but hopefully one that most could accept. This approach too could deliver normative effectiveness.

However, neither of these options was instigated in this case. In the absence of any attempt to agree clear normative goals prior to commencing the strategic assessment, it was inevitable that the process would not meet the expectations of all stakeholders with their different values and visions for a sustainable future (see for example The Wilderness Society 2010). The increasing disillusionment of various stakeholders with the process as it progressed described in section 3 suggests the answer to the question posed by Bond, Pope et al. (2015) must be 'no'.

\subsection{Pluralism}

How, and to what extent, are affected and concerned parties accommodated into and satisfied by the assessment process?

Efforts were made initially to ensure that different voices were heard in the assessment process, notably through the support provided by the Government of Western Australia to the KLC and TOTF to enable Indigenous people to conduct their own site selection process and the Indigenous Impacts Assessment to be completed in accordance with the Terms of Reference of the strategic assessment process. However the very different views expressed by the regulator and Traditional Owners on the environmental acceptability of Gourdon Bay highlight how significantly different some views may be: the EPA concluded that Gourdon Bay was the 'least environmentally constrained' of the four shortlisted sites, at around the same time that the TOTF had withdrawn it from its own short-list on environmental grounds.

There was little evidence of willingness to engage with pluralism in the statutory strategic assessment process; numerous concerns raised through the public submissions process, in the media, and in the protests were not addressed to the satisfaction of the many affected and concerned parties (The Wilderness Society 2010, Beckwith 2012). We therefore conclude that 
although initial intentions may have been good the strategic assessment did not perform well overall in terms of pluralism.

\subsection{Knowledge and learning}

How, and to what extent, does the assessment process facilitate instrumental and conceptual learning?

Instrumental learning relates to whether or not information was obtained through the assessment process that improved understanding of a situation (i.e. the acquisition of knowledge within a frame). This is closely related to direct substantive effectiveness, which asks whether the assessment process can be demonstrated to have informed and influenced decision-making. As discussed in Section 4.2, it is clear that information gathered from various sources during the site selection process did inform the NDT process, the EPA's advice to Government, and ultimately the selection of the preferred site at James Price Point. Instrumental learning is more difficult to discern in the statutory strategic assessment process, especially since much of the required information was produced too late to influence decision-making.

In contrast, conceptual learning relates refers to a modification in frame. Such a process of reframing usually results from some kind of cognitive dissonance whereby one's frame is challenged by new information or perspectives, for example through a process of deliberation with a range of stakeholders with varying worldviews (Hartz-Karp, Pope et al. 2015). As discussed in the previous section, no genuine opportunities for deliberation were provided for within the Browse LNG Precinct strategic assessment, and hence we consider it unlikely that significant conceptual learning occurred. As our methodology is based upon secondary sources, and we have not interviewed stakeholders about their experiences of the process, we are not able to verify this view.

In summary we consider that there was evidence of instrumental learning in the NDT site selection process but that it is unclear whether conceptual learning, or learning of any types at other stages of the process occurred.

\section{Discussion}

In this section we reflect upon our research aim: to test the broader utility of the Bond, Pope et al. (2015) effectiveness framework by applying it to a specific strategic assessment case study rather than a system-wide review of sustainability assessment, and to propose any necessary refinements to the framework as a result of this evaluation.

We note that in some cases the two levels of evaluation (specific case study versus system-wide review) are dependent upon each other; for example at a systems level it would be appropriate to ask when considering procedural effectiveness whether appropriate (context-specific) procedures and legal mechanisms are established within the jurisdiction, and then at the case study level to evaluate compliance with these procedures. In this case, in the absence of clear procedures at the time of the assessment, we were only able to undertake the evaluation using generic features of best practice strategic assessment. Essentially, procedural effectiveness for individual cases is dependent on the specific legal process which will vary between all jurisdictions. Use of the effectiveness framework therefore needs to be underpinned by a clear statement of the procedural expectations being used. If local procedures are used, then cross comparison with other jurisdictions 
is not possible. If international best practice is used, stakeholders involved in the practice being evaluated can be criticised, in some eyes, unfairly.

Overall, we found the framework, with the minor modifications to wording posed in Section 3, to be broadly appropriate and thus useful. This is because the structure of the framework enabled us to reflect meaningfully on our case study and to identify strengths and weaknesses, although we do develop some further, more substantial modifications and improvements in the discussion that follows. These arise from both conceptual and pragmatic reflections on the use of the framework.

We initially considered whether the application of the framework has added any value in terms of insights into the case study over the works already pblished on the subject (Beckwith 2012, Marsden 2013, O'Faircheallaigh 2015), and conversely whether it fails to identify issues raised by these studies. We drew extensively on each of these works in our analysis in Section 5, but found that different works discussed different dimensions of effectiveness with different areas of focus, as summarised in Table 1.

\begin{tabular}{|l|l|l|l|}
\hline Dimension & Beckwith (2012) & Marsden (2013) & $\begin{array}{l}\text { O'Faircheallaigh } \\
\text { (2015) }\end{array}$ \\
\hline $\begin{array}{l}\text { Procedural } \\
\text { effectiveness }\end{array}$ & $\begin{array}{l}\text { Yes w.r.t. coverage of } \\
\text { social issues }\end{array}$ & $\begin{array}{l}\text { Yes w.r.t. } \\
\text { consideration of } \\
\text { alternatives }\end{array}$ & $\begin{array}{l}\text { Yes w.r.t. Indigenous } \\
\text { engagement }\end{array}$ \\
\hline $\begin{array}{l}\text { Substantive } \\
\text { effectiveness }\end{array}$ & $\begin{array}{l}\text { Yes w.r.t. } \\
\text { implementation of } \\
\text { social outcomes }\end{array}$ & No & No \\
\hline $\begin{array}{l}\text { Transactive } \\
\text { effectiveness }\end{array}$ & No & No & $\begin{array}{l}\text { Yes w.r.t. impact on } \\
\text { timelines of political } \\
\text { and other pressures }\end{array}$ \\
\hline $\begin{array}{l}\text { Normative } \\
\text { effectiveness }\end{array}$ & $\begin{array}{l}\text { Yes w.r.t. potential } \\
\text { alternative goals of } \\
\text { process }\end{array}$ & $\begin{array}{l}\text { Yes w.r.t. implicit and } \\
\text { (lack of) explict goals } \\
\text { of process }\end{array}$ & $\begin{array}{l}\text { Yes w.r.t. implicit } \\
\text { goals of process }\end{array}$ \\
\hline Pluralism & $\begin{array}{l}\text { Yes w.r.t. views of } \\
\text { community }\end{array}$ & No & $\begin{array}{l}\text { Yes w.r.t. Indigenous } \\
\text { perspective }\end{array}$ \\
\hline $\begin{array}{l}\text { Knowledge and } \\
\text { learning }\end{array}$ & No & No & No \\
\hline
\end{tabular}

Table 1: Framework coverage of existing works reviewed

Table 1 demonstrates that each work reviewed took a particular perspective, that while illuminating, did not evalaute the overall effectiveness of the strategic assessment (and neither did they purport to do so). A more comprehensive evaluation has been achieved by combining these perspectives together with our own document review and personal insights. We found that the application of the framework as a whole adds value in terms of highlighting the inter-dependencies of the dimensions. For example we found some limitations in procedural effectiveness with respect to the quality and timeliness of information generated (Section 5.1), which in turn undermined the substantive effectiveness of the assessment (Section 5.2) in that decision-making could not be informed by information that wasn't robust and/or wasn't available in time. We were also able to hypothesise that efforts to maintain transactive effectiveness, specifically timeliness and efficiency, probably undermined both procedural and substantive effectiveness. 
However, these studies also highlighted aspects of the case study that the framework was less successful in identifying. Issues of politics and power were a focus particularly of O'Faircheallaigh (2015), but also more implicitly in Beckwith (2012) and Marsden (2013). These aspects are worthy of further conceptualisation within the effectiveness framework, and we return to them later in this section.

Another important point raised by Beckwith (2012) and also Wesley (2013) is that of the 'collateral social damage' of the assessment process, in the form of ongoing conflict between different sectors of the community and unforeseen socio-economic impacts on the town associated with unfulfilled expectations. These are social impacts that are unlikely to be foreseen and assessed in typical social impact assessment (SIA) practice. Hartz-Karp, Pope et al. (2015) discuss this issue and propose that the scenario of the development not proceeding should be included in SIA. These unplanned sideeffects can also be conceptualised as substantive outcomes; in this case it could be argued that they represent a negative contribution to social sustainability. This highlights the need for further conceptualisation of substantive effectiveness to include direct, indirect/incremental, and also unintended outcomes.

Other points of reflection emerge from our own analysis in Section 5. Firstly we found some conceptual overlap between knowledge and learning and substantive effectiveness, since knowledge and learning are the mechanisms through which substantive outcomes are delivered either directly by informing decision-making around a specific assessment, or indirectly/incrementally by leading to changes in governance and societal context over time. We have also argued that conceptual learning is more likely to occur when there are opportunities for meaningful deliberation between stakeholders with different views and beliefs, and hence it is related to aspects of procedural effectiveness. From a more pragmative perspective, it is difficult to evaluate knowledge and learning either in a single case study or a system-wide review without the application of very different methods. There is therefore an argument that knowledge and learning is not necessary as a separate category within an effectiveness framework; however, we argue here for its retention as a key measure of system effectiveness recognising its importance for system development. We propose that learning (which is a term that already implies knowledge gain) is included as a consideration of substantive effectiveness in system-wide reviews.

We also note conceptual overlap between normative effectiveness and pluralism, as whether or not affected and concerned parties feel that they have been accommodated in the process (pluralism) will to a large extent depend upon whether they agree with the overall goal of the process itself (normative). The fundamental problem in terms of achieving normative effectiveness in this case was that the normative goals of the process were not defined and agreed up front. Using the framework of Hisschemöller and Hoppe (1996), this case study would thus be classifed as an 'unstructured problem' where neither the goals nor the means of achieving them are agreed, or at best a moderately structured (means) one in that it could be argued that the means and knowledge bases were agreed even if the goal was not. The goals were therefore open to interpretation by different stakeholders with different values and beliefs, as well as being subject to continual change depending on the political climate. Although we alluded to the potential to collaboratively identify normative goals at the outset of an assessment based on the work of Hartz-Karp, Pope et al. (2015), this may often be unrealistic given that assessments are procedurally constrained with legally enforcable requirements. In fact Owens, Rayner et al. (2004) suggest that such an approach may 
even exacerbate conflict, by exposing the depth of world view incompatibility. We believe that the lack of explicit and agreed normative goals contributed to a failure to meet the expectations of a broad range of stakeholders in this case, although we cannot verify this without conducting stakeholder interviews.

The inclusion of pluralism in an effectivness framework focussed on the system level is based on the inadequacies of the technical-rational model on which EIA was originally based, given their potential to allow bias, and it is argued that such criticisms have led to more deliberative approaches which introduce a wider set of values into decision-making (Morgan 2012). Thus increased pluralism has been seen as a means of controlling bias, which simultaneously increases the legitimacy of the process. At the system level this has validity, but for an individual case study, evaluation of pluralism is difficult to distinguish from procedural effectiveness, as there will be mandated participation requirements. However, as Owens, Rayner et al. (2004), p1947 say, "appraisal based on contested judgments or frames loses legitimacy and becomes practically inadequate for delivering reasonably consensual policy outcomes". Taking our cue from Owens, Rayner et al. (2004), we find the concept of legitimacy to be a more useful one in reflecting on impact assessment effectiveness as it encompasses normative considerations. As such, legitimacy incorporates both considerations of the effectiveness of stakeholder engagement (pluralism) and views about the ability of the process to deliver what observers wish to see (normative effectiveness).

The legitimacy of an impact assessment process has been defined recently as "one which all stakeholders agree is fair and which delivers an acceptable outcome for all parties" (Bond, Pope et al. 2016, p.188), and Gross (2007) has demonstrated empirically how process legitimacy is affected firstly by the extent to which the values and attitudes of stakeholders align with the goals of the development, and secondly by perceptions of the fairness of the process itself, including the adequacy of opportunities for engagement. Legitimacy also implicitly reflects concerns about power and particularly its misuse within the process. We therefore propose to replace both normative effectiveness and pluralism by a single category of legitimacy effectiveness and consider that a suitable legitimacy effectiveness question is: Was the assessment process perceived to be legitimate by a wide range of stakeholders? The answer to this question in this case would have been 'no', for reasons already discussed.

A final point of reflection is that our effectiveness framework enables evaluation of the effectiveness of an impact assessment process, but does not provide any insights into why a process is effective or ineffective (despite the current wording of some prompting questions implying this). The importance of understanding causal pathways has been widely recognised, including how aspects of the policy, institutional and societal context influence effectiveness (Runhaar and Driessen 2007, Bina 2008, Lyhne, van Laerhoven et al. 2015); how power plays out in impact assessment (Cashmore, Richardson et al. 2010, Cashmore and Richardson 2013, Hansen, Kørnøv et al. 2013) and how learning influences substantive outcomes (Sinclair, Diduck et al. 2008, Jha-Thakur, Gazzola et al. 2009). This is all clearly important work contributing to a deeper understanding of impact assessment effectiveness. 


\section{Conclusions}

We set out to apply the effectiveness framework of Bond, Pope et al. (2015), initially developed for system-wide reviews of sustainability assessment, to the evaluation of specific impact assessment processes more generally. To do this we tested the framework against the strategic assessment of the proposed Browse LNG Precinct in Western Australia, a process characterised by controversy and conflict. This exercise was successful in that the framework enabled a comprehensive evaluation of the case study, even based on document review alone, and highlighted issues not previous raised by earlier critiques of the process undertaken from particular perspectives. Our analysis demonstrates the inter-relatedness of various effectiveness dimensions, and also the interplay between systemwide effectiveness and effectiveness of individual case studies.

We found some opportunities to refine the framework, firstly by adjusting the wording of the prompting questions to make them more applicable to impact assessment in general, and secondly by replacing the categories of normative effectiveness and pluralism with legitimacy. Our revised framework is therefore:

Procedural effectiveness: Have appropriate processes been followed that reflect institutional and professional standards and procedures?

Substantive effectiveness: To what extent does the assessment lead to changes in process, actions, learning or outcomes?

Transactive effectiveness: To what extent, and by whom, is the outcome of conducting the assessment considered to be worth the time and cost involved?

Legitimacy: Was the assessment process perceived to be legitimate by a wide range of stakeholders?

Acknowledging that this is an analytical and not an explanatory framework, we believe that it is sufficiently comprehensive to be a useful tool for effectiveness evaluations into the future. We have identified that there is opportunity for further work in expanding the conceptualisation of substantive effectiveness to include unintended consequences of impact assessment processes, and in further unpacking the factors contributing to perceptions of legitimacy. 


\section{References}

Argyris, C. and D. Schön (1996). Organizational Learning II, Addison-Wesley Publishing Company, Inc. Bache, S., J. Bailey and N. Evans (1996). "Interpreting the Environmental Protection Act 1986 (WA): Social impacts and the environment refined." Environmental Planning and Law Journal 13: 487-492. Baker, D. C. and J. N. McLelland (2003). "Evaluating the effectiveness of British Columbia's environmental assessment process for first nations' participation in mining development." Environmental Impact Assessment Review 23(5): 581-603.

Beckwith, J. (2012). "A social impact perspective of the Browse LNG Precinct strategic assessment in Western Australia." Impact Assessment and Project Appraisal 30(3): 189-194.

Bina, O. (2008). "Context and systems: thinking more broadly about effectiveness in strategic environmental assessment in China." Environmental management 42(4): 717-733.

Bina, O., W. Jing, L. Brown and M. R. Partidário (2011). "An inquiry into the concept of SEA effectiveness: towards criteria for Chinese practice." Environmental Impact Assessment Review 31(6): 572-581.

Bond, A., T. Dockerty, A. Lovett, A. B. Riche, A. J. Haughton, D. A. Bohan, R. B. Sage, I. F. Shield, J. W. Finch, M. M. Turner and A. Karp (2011). "Learning how to deal with values, frames and governance in Sustainability Appraisal." Regional Studies 45(8): 1157-1170.

Bond, A. and A. Morrison-Saunders (2011). "Re-evaluating Sustainability Assessment: Aligning the Vision and the Practice." Environmental Impact Assessment Review 31(1): 1-7.

Bond, A., A. Morrison-Saunders and R. Howitt (2013). Chapter 8: Framework for comparing and evaluating sustainability assessment practice. Sustainability Assessment: Pluralism, Practice and Progress. A. Bond, A. Morrison-Saunders and R. Howitt. Abingdon, Oxon, Routledge: 117-131. Bond, A., A. Morrison-Saunders and R. Howitt, Eds. (2013). Sustainability assessment: Pluralism, practice and progress. Abingdon, Oxon, Routledge.

Bond, A., J. Pope and A. Morrison-Saunders (2015). Chapter 1: Introducing the roots, evolution and effectiveness of sustainability assessment. Handbook of Sustainability Assessment. A. MorrisonSaunders, J. Pope and A. Bond, Edward Elgar.

Bond, A., J. Pope, A. Morrison-Saunders and F. Retief (2016). "A game theory perspective on environmental assessment: What games are played and what does this tell us about decision making rationality and legitimacy?" Environmental Impact Assessment Review 57: 187-194.

Bond, A., J. Pope, A. Morrison-Saunders, F. Retief and J. A. Gunn (2014). "Impact assessment: Eroding benefits through streamlining?" Environmental Impact Assessment Review 45: 46-53. Burrell, A. (2011). Maverick Cousins shifts sights from Gunns to Woodside. The Australian. Carpenter, A. (2006). West Kimberley onshore liquefied natural gas processing facilities: statement by premier, Legislative Assembly, Western Australia, 21 November

Cashmore, M., A. Bond and D. Cobb (2008). "The role and functioning of environmental assessment: Theoretical reflections upon an empirical investigation of causation." Journal of Environmental Management 88: 1233-1248.

Cashmore, M., R. Gwilliam, R. Morgan, D. Cobb and A. Bond (2004). "The interminable issue of effectiveness: substantive purposes, outcomes and research challenges in the advancement of environmental impact assessment theory." Impact Assessment and Project Appraisal 22 (4): 295-310. Cashmore, M. and T. Richardson (2013). "Power and environmental assessment: Introduction to the special issue." Environmental Impact Assessment Review 39: 1-4.

Cashmore, M., T. Richardson, T. Hilding-Ryedvik and L. Emmelin (2010). "Evaluating the effectiveness of impact assessment instruments: Theorising the nature and implications of their political constitution." Environmental Impact Assessment Review 30: 371-379.

Chanchitpricha, C. and A. Bond (2013). "Conceptualising the effectiveness of impact assessment processes." Environmental Impact Assessment Review 43: 65-72.

DoIR (2007). Northern Development Taskforce Terms of Reference. Perth, Western Australia, Department of Industry and Resources. 
DSD (2010a). Browse LNG Precinct Strategic Assessment Report (Draft for Public Comment) Part 1: Executive Summary. Perth, Department of State Development, Western Australia.

EPA (2008). Kimberley LNG Precinct. Review of potential sites for a proposed multi-user liquefied natural gas processing precinct in the Kimberley region (Report 1306). Perth, Western Australia, Environmental Protection Authority.

Fischer, T. and P. Gazzola (2006). "SEA effectiveness criteria- equally valid in all countries? The case of Italy." Environmental Impact Assessment Review 26(4): 396-409.

Fischer, T. B. (2002). "Strategic environmental assessment performance criteria - the same requirements for every assessment?" Journal of Environmental Assessment, Policy and Management 4(1): 83-99.

GCA (2008). Browse Basin Gas Technical Report - Development Options Study, Report 1 of 3: LNG Plant Site Selection Validation. Perth, Western Australia, Gaffney, Cline and Associates on behalf of the Northern Development Taskforce.

GHD (2009). Comparative Analysis of the Feasibility of Alternative Locations for the Development of a Liquefied Natural Gas Precinct, Canberra, Australia, Department of the Environment, Water, Heritage and the Arts.

Gross, C. (2007). "Community perspectives of wind energy in Australia: The application of a justice and community fairness framework to increase social acceptance" Energy Policy 35: 2727-2736.

Hacking, T. and P. Guthrie (2008). "A framework for clarifying the meaning of Triple Bottom-Line, Integrated, and Sustainability Assessment." Environmental Impact Assessment Review 28(1): 73-89. Hansen, A. M., L. Kørnøv, M. Cashmore and T. Richardson (2013). "The significance of structural power in Strategic Environmental Assessment." Environmental Impact Assessment Review 39: 37-45. Hartz-Karp, J., J. Pope and S. Petrova (2015). Chapter 16: A Deliberative Collaborative Governance approach to sustainability assessment Handbook of Sustainability Assessment. A. MorrisonSaunders, J. Pope and A. Bond. Cheltenham, UK, Edward Elgar. Hisschemöller, M. and R. Hoppe (1996). "Coping with intractable controversies: The case for problem structuring in policy design and analysis." Knowledge and Policy 8(4): 40-60.

International Association for Impact Assessment. (2002). "Strategic environmental assessment performance criteria.", from http://www.iaia.org/Publications/sp1.pdf 2002 [Accessed 3 Feb 2003, IAIA].

Jha-Thakur, U., P. Gazzola, D. Peel, T. B. Fischer and S. Kidd (2009). "Effectiveness of strategic environmental assessment - the significance of learning." Impact Assessment and Project Appraisal 27(2): 133-144.

Jones, C., M. Baker, J. Carter, S. Jay, M. Short and C. Wood, Eds. (2005). Strategic Environmental Assessment and Land Use Planning: An International Evaluation. London, Earthscan Publications Ltd. Lyhne, I., F. van Laerhoven, M. Cashmore and H. Runhaar (2015). "Theorising ElA effectiveness: A contribution based on the Danish system." Environmental Impact Assessment Review.

Marsden, S. (2013). "Protecting Heritage On Australia'S Coasts: A Role For Strategic Environmental Assessment?" Journal of Environmental Assessment Policy and Management 15(03): 1350014. Morgan, R. K. (2012). "Environmental impact assessment: the state of the art." Impact Assessment and Project Appraisal 30(1): 5-14.

Morrison-Saunders, A., J. Pope, J. Gunn, A. Bond and F. Retief (2014). "Strengthening impact assessment: A call for integration and focus." Impact Assessment and Project Appraisal 32(1): 2-8.

Morrison-Saunders, A. and R. Thérivel (2006). "Sustainability integration and assessment." Journal of Environmental Assessment, Policy and Management 8(3): 281-298.

NDT (2008a). Northern Development Taskforce Interim Report Perth, Western Australia, Northern Development Taskforce.

NDT (2008b). Northern Development Taskforce Site Evaluation Report Parts A and B. Perth, Western Australia, Northern Development Taskforce.

NDT (2008c). Northern Development Taskforce Final Site Evaluation Report. Perth, Western Australia, Northern Development Taskforce. 
Nilsson, M. (2005). "Learning, frames, and environmental policy integration: the case of Swedish energy policy." Environment and Planning C: Government and policy 23(2): 207-226.

O'Faircheallaigh, C. (2009). "Effectiveness in social impact assessment: Aboriginal peoples and resource development in Australia." Impact Assessment and Project Appraisal 27(2): 95-110. O'Faircheallaigh, C. (2015). "ESD and community participation: the Strategic Assessment of the proposed Kimberley LNG Precinct, 2007-2013." Australasian Journal of Environmental Management 22(1): 46-61.

Owens, S., T. Rayner and O. Bina (2004). "New agendas for appraisal: reflections on theory, practice and research." Environment and Planning A 36(11): 1943-1959.

Pope, J. (2007). Facing the Gorgon: Sustainability assessment and policy learning in Western Australia. PhD, Murdoch University.

Pope, J. and W. Grace (2006). "Sustainability assessment in context: Issues of process, policy and governance." Journal of Environmental Assessment, Policy and Management 8(3): 373-398.

Retief, F. (2007). "Effectiveness of strategic environmental assessment (SEA) in South Africa." Journal of environmental assessment policy and management 9(01): 83-101.

Rozema, J. G. and A. J. Bond (2015). "Framing effectiveness in impact assessment: Discourse accommodation in controversial infrastructure development." Environmental Impact Assessment Review 50: 66-73.

Runhaar, H. and P. P. Driessen (2007). "What makes strategic environmental assessment successful environmental assessment? The role of context in the contribution of SEA to decision-making." Impact assessment and project appraisal 25(1): 2-14.

Sadler, B. (1996). International Study of the Effectiveness of Environmental Assessment - Final Report, Canadian Environmental Assessment Agency and the International Association for Impact Assessment.

Sánchez, L. E. and A. Morrison-Saunders (2011). "Learning about knowledge management for improving environmental impact assessment in a government agency: The Western Australian experience." Journal of Environmental Management 92: 2260-2271.

Sheate, W. R. (2009). The Evolving Nature of Environmental Assessment and Management: Linking Tools to Help Deliver Sustainability - Tools, Techniques \& Approaches for Sustainability. Tools, Techniques and Approaches for Sustainability: Collected Writings in Environmental Assessment Policy and Management. W. R. Sheate. Singapore, World Scientific: 1-29.

Sinclair, J., A. Diduck and P. Fitzpatrick (2008). "Conceptualizing learning for sustainability through environmental assessment: Critical reflections on 15 years of research." Environmental Impact Assessment Review 28(7): 415-428.

Stoeglehner, G., A. Morrison-Saunders and G. Early (2010). "Comparing legislative mechanisms for SEA screening and decision-making: Austrian and Australian experiences." Journal of Environmental Assessment, Policy and Management 12(4): 399-423.

The Wilderness Society (2010). A citizen's guide to the Kimberley 'gas hub strategic assessment': A politicised and compromised process Perth, Western Australia, The Wilderness Society. Theophilou, V., A. Bond and M. Cashmore (2010). "Application of the SEA Directive to EU structural funds: Perspectives on effectiveness." Environmental Impact Assessment Review 30(2): 136-144. Van Doren, D., P. Driessen, B. Schijf and H. Runhaar (2013). "Evaluating the substantive effectiveness of SEA: Towards a better understanding." Environmental impact assessment review 38: 120-130. Wallington, T., O. Bina and W. Thissen (2007). "Theorising strategic environmental assessment: Fresh perspectives and future challenges." Environmental Impact Assessment Review 27: 569-584.

Wesley, A. (2013). The socio-political construction and experience of corporate social responsibility (CSR): An investigation into the conflict surrounding the James Price Point LNG precinct, Kimberley, Western Australia. PhD, Curtin University.

Wood, C. (2003). Environmental impact assessment: A comparative review. Harlow, Prentice-Hall. 